1 Institute of Applied Health Research, University of Birmingham,

Birmingham, UK

2 Warwick Medical School, University of Warwick, Coventry, UK

3 Association of Schools of Public Health in the European Region (ASPHER)

Correspondence to: S Haroon s.haroon@bham.ac.uk

Cite this as: BMJ 2020;370:m3181 http://dx.doi.org/10.1136/bmj.m3181 Published: 14 August 2020

\section{Covid-19: breaking the chain of household transmission}

\author{
We urgently need new measures to protect household contacts \\ Shamil Haroon, ${ }^{1}$ Joht Singh Chandan, ${ }^{1,2}$ John Middleton, ${ }^{3}$ Kar Keung Cheng ${ }^{1}$
}

The UK is one of the countries most severely affected by covid-19. Recent outbreaks in English towns such as Oldham, probably involving transmission within large multigenerational households, show the importance of getting the right public health measures in place now to prevent more widespread surges in infections. ${ }^{1}$

Current test and trace policies have mainly focused on preventing spread in care homes, hospitals, and in the community. ${ }^{2}$ However, contact within households is thought to be responsible for roughly $70 \%$ of SARS-CoV-2 transmission when widespread community control measures are in place. ${ }^{3}$ In Wuhan, the reproduction number $(\mathrm{R})$ dropped from 3.54 to 1.18 after lockdown and cordon sanitaire. But the epidemic was only brought under complete control when Fangcang (field) hospitals were introduced to isolate cases outside the home, with $\mathrm{R}$ dropping to 0.51 after two weeks. ${ }^{4}$

Current UK guidance advises household contacts to isolate within the same home as the index case for 14 days. 5 They make up the majority of contacts for infected individuals and are likely to remain exposed to the infected household member during this period of isolation. ${ }^{6}$ Despite guidance advising household members to socially distance, contacts are likely to interact repeatedly-during mealtimes, for example-and to share facilities such as bathrooms.

We know that transmission is more likely to occur indoors than outdoors. ${ }^{7}$ The cumulative risk to household contacts from an infected person is likely to be substantial during peak viral shedding. In one study in New York State, 38\% of household contacts tested positive for SARS-Cov-2, and similar secondary infection rates have been reported in China. 89

Transmission may be even higher among household contacts of essential workers, who are at greater risk of being infected than the general population. ${ }^{10}$

Household members who are older, have underlying medical conditions, or share a bed or vehicle with the index case are the most susceptible. ${ }^{91112}$ Children seem to be at lower risk of being infected. ${ }^{13}$ However, their stool samples and nasopharyngeal swabs can remain positive for SARS-CoV-2 for more than two weeks after symptom resolution, ${ }^{14}$ although their role in transmission remains to be established.

Governments should consider new public health measures to prevent household transmission as we prepare for a potential second wave. Household quarantine is likely to remain an important pandemic control measure, and government support for people quarantined at home is conspicuously absent in the UK: this position has been challenged by independent experts. ${ }^{15}$

\section{Effective isolation}

Effective isolation of index cases from household members could reduce secondary infections. ${ }^{12}$ Wearing masks within quarantined households may help, particularly if used by the index case as soon as infection is suspected. ${ }^{16}$ The World Health Organization recommends that infected people and unavoidable close contacts, particularly those in vulnerable groups, should wear medical masks, but Public Health England does not currently recommend this. Other measures that should be considered (and evaluated) include clear advice on enhanced personal hygiene; cleaning and disinfecting shared toilets and other common spaces, door handles, and touch points; and staggering mealtimes.

People who are unable to self-isolate safely at home could be accommodated in special isolation facilities such as hotels and hostels, an approach adopted by some other countries, including Italy, Finland, and Lithuania. ${ }^{17}$ In China, field hospitals were created to manage and strictly isolate patients with mild-to-moderate covid-19. ${ }^{18}$ Nightingale hospitals in the UK could be similarly repurposed to support isolation of infected people with mild-to-moderate disease. As medical and nursing care needs are mostly modest, the cost would be relatively low. However, such a system depends on access to rapid testing for anyone with symptoms or possible exposure so that infection can be confirmed and isolation started before transmission occurs. It would also require public trust that isolation in these facilities would be voluntary, safe, and supportive.

Important questions about household transmission remain. Research should be done to identify the determinants of household transmission and the optimal strategies for isolating cases and protecting household contacts. These strategies will be particularly important for those at higher risk of adverse outcomes, including ethnic minority communities, people in low income households, and those living in urban areas with overcrowded housing.

Until an effective vaccine is widely available, strategies to prevent household transmission and to support those in quarantine will be vital and should be a core part of any government's strategy. It is high time that the UK government amend its mantra of "test and trace" to "test, trace, isolate, and support."

Competing interests: We have read and understood BMJ policy on declaration of interests and have no interests to declare.

Provenance and peer review: Not commissioned; externally peer reviewed. 
1 Oldham takes measures to avoid full coronavirus lockdown. Guardian 2020 Jul 28.

https://www.theguardian.com/uk-news/2020/ju/28/oldham-greater-manchester-takes-measuresto-avoid-full-coronavirus-covid-19-lockdown

2 UK Government. COVID-19: number of outbreaks in care home-management information, 7 Jul 2020. https://www.gov.uk/government/statistical-data-sets/covid-19-number-of-outbreaks-incare-homes-management-information

3 Shen M, Peng Z, Guo Y, etal. Assessing the effects of metropolitan-wide quarantine on the spread of COVID-19 in public space and households. Int Infect Dis 2020;96:503-5. doi: 10.1016/i.iji.2020.05.019 pmid: 32416146

4 Hao X, Cheng S, Wu D, Wu T, Lin X, Wang C. Reconstruction of the full transmission dynamics of COVID-19 in Wuhan. Nature 2020. [Epub ahead of print.] doi: 10.1038/s41586-020-2554-8 pmid: 32674112

5 UK Government. COVID-19: guidance for households with possible coronavirus infection. 7 July 2020. https://www.gov.uk/government/publications/covid-19-stay-at-home-guidance

6 Yu H-J, Hu Y-F, Liu X-X, etal. Household infection: the predominant risk factor for close contacts of patients with COVID-19. Travel Med Infect Dis 2020;36: doi: 10.1016/j.tmaid.2020.101809 pmid: 32592904

7 Nishiura $\mathrm{H}$, Oshitani $\mathrm{H}$, Kobayashi $\mathrm{T}$, et al. Closed environments facilitate secondary transmission of coronavirus disease 2019 (COVID-19). medRxiv 2020.02.28.20029272. [Preprint.] 2020. doi: 10.1101/2020.02.28.20029272

8 Rosenberg ES, Dufort EM, Blog DS, etalNew York State Coronavirus 2019 Response Team. Covid-19 testing, epidemic features, hospital outcomes, and household prevalence, New York State-March 2020. Clin Infect Dis 2020;. doi: 10.1093/cid/ciaa549 pmid: 32382743

9 Wu J, Huang Y, Tu C, etal. Household transmission of SARS-CoV-2, Zhuhai, China[PubMed.]. Clin Infect Dis 2020 [Epub ahead of print.]pmid: 32392331

10 McDade TW, McNally E, Zelikovich A, et al. High seroprevalence for SARS-CoV-2 among household members of essential workers detected using a dried blood spot assay. medRxiv 2020.06.01.20119602. [Preprint.] 2020. doi: 10.1101/2020.06.01.20119602

11 Jing Q-L, Liu M-J, Zhang Z-B, etal. Household secondary attack rate of COVID-19 and associated determinants in Guangzhou, China: a retrospective cohort study. Lancet Infect Dis 2020: doi: 10.1016/S1473-3099(20)30471-0. pmid: 32562601

12 Li W, Zhang B, Lu J, etal. The characteristics of household transmission of COVID-19. Clin Infect Dis 2020;; [Epub ahead of print.]. doi: 10.1093/cid/ciaa450 pmid: 32301964

13 Dattner I, Goldberg Y, Katriel G, et al. The role of children in the spread of COVID-19: using household data from Bnei Brak, Israel, to estimate the relative susceptibility and infectivity of children. medRxiv 2020.06.03.20121145. 2020. [Preprint.] doi: 10.1101/2020.06.03.20121145

14 Mao LI, Xu J, Xu ZH, etal. A child with household transmitted COVID-19. BMC Infect Dis 2020;20:329. doi: 10.1186/s12879-020-05056-w pmid: 32381073

15 Independent SAGE. COVID-19: what are the options for the UK? Recommendations for government based on an open and transparent examination of the scientific evidence. 2020. http://www.independentsage.org/wp-content/uploads/2020/05/The-Independent-SAGE-Report.pdf.

16 Wang Y, Tian H, Zhang L, etal. Reduction of secondary transmission of SARS-CoV-2 in households by face mask use, disinfection and social distancing: a cohort study in Beijing, China. BMJ Glob Health 2020;5:. doi: 10.1136/bmigh-2020-002794 pmid: 32467353

17 How do measures for isolation, quarantine, and contact tracing differ among countries? Cross-country analysis. 19 May 2020. https://analysis.covid19healthsystem.org/index.php/2020/05/19/how-do-measures-for-isolation-quarantine-and-contact-tracing-differamong-countries/

18 Chen S, Zhang Z, Yang J, etal. Fangcang shelter hospitals: a novel concept for responding to public health emergencies. Lancet 2020;395:1305-14. doi: 10.1016/S0140-6736(20)30744-3 pmid: 32247320

This article is made freely available for use in accordance with BMJ's website terms and conditions for the duration of the covid-19 pandemic or until otherwise determined by BMJ. You may use, download and print the article for any lawful, non-commercial purpose (including text and data mining) provided that all copyright notices and trade marks are retained. 